\title{
Assessment of Platelet Profile of Healthy Volunteers in the Trimesters of Pregnancy in Benin City, Nigeria
}

\section{*10MOROGIUWA A, AIGBORHUAN HA}

\author{
Department of Physiology, School of Basic Medical Sciences, \\ College of Medical Sciences, \\ University of Benin, Benin city \\ Corresponding author: E-mail: ask4ade2006@yahoo.com Phone number: +234(0)7039460340
}

\begin{abstract}
These studies aimed at assessing platelet profile in the three trimesters of pregnancy.Subjects were apparently healthy volunteers who were staff, students and antenatal patients of a Hospital in Benin. Platelet profile was assessed using Swelab Alfa Basic model Haematological Analyser (Boule Medical AB, Stockholm, Sweden). The results were presented as mean \pm SEM in tables and graphs and analysed using One Way Analysis of Variance and Duncan post Hoc test and $\mathrm{p}<0.05$ was considered significant. The study showed that platelet count $x 10^{3} / \mu 1(277.83 \pm$ 36.33; first trimester $>193.60 \pm 13.15$; second trimester $>185.50 \pm 11.58$; third trimester) and plateletcrit in percentage $(0.22 \pm 0.03$; first trimester $>0.17 \pm 0.01$; second trimester $>0.16 \pm 0.01$; third trimester $)$ reduced progressively as pregnancy advanced and this was statistically significant $(\mathrm{p}<0.05)$ when compared to control of $276.17 \pm 34.32 \times 10^{3} / \mu 1$ and $0.20 \pm 0.20$ respectively. A similar pattern was observed for Mean Platelet Volume (MPV). However, Platelet Width Density $(\mathrm{PDW})$ in percentage increased $(10.52 \pm 0.22$; first trimester $<13.44 \pm 0.30$; second trimester $<13.65 \pm$ 0.41; third trimester) as pregnancy advanced. Thus PDW compensates for these reductions and a lack of this compensatory increase may aggravate the effect of thrombocytopenia in pregnancy. @JASEM
\end{abstract}

\section{http://dx.doi.org/10.4314/jasem.v20i4.21}

Keywords: Platelet Count, Plateletcrit, Mean Platelet Volume, Platelet Distribution Width, Trimesters, Pregnancy

Platelet studies have evolved from its customary function in hemostasis to other functions such as inflammation, innate immunity, wound healing and angiogenesis (Kakali, 2013). In pregnancy several hematological, biochemical and hemodynamic modifications occur as part of the physiological adaptation of the body to this condition (RodríguezDennen, 2011). These adaptations are meant to maintain the maternal, fetal and uteroplacental homestasis. Thrombocytes or platelets, red cells and white cells are essential for hemostasis, transport of oxygen and immunity respectively and their physiologic modification are particularly important during pregnancy. However, there have been controversies about the pattern of platelet profile in normal pregnancy, for instance Mohapatra et al (2007) reported that platelet count increased as pregnancy advanced. This is in contrast to other studies that reported a fall in platelet count as pregnancy advanced (Bonar et al., 1969; Sejeny et al., 1975; Karim et al., 1992). Also, some researchers reported that there was no change in the platelets count as pregnancy advanced (Todd et al., 1965; Ratnoff., 1954; Tygart et al., 1986) while others reported a fall of platelet count from the first trimester and a rise in the third trimester (AmahTariah et al., 2011). Amongst Chinese women, a gradual decrease in platelet count with no change in mean platelet volume has been reported (Liu et al.,
2011) Most of the studies done on platelet in pregnancy did not involve other platelet parameters such as Mean Platelet Volume (MPV), Plateletcrit (PCT) and Platelet Density Width (PDW). This study is therefore aimed at assessing plate count and these additional parameters in the three trimesters of pregnancy.

\section{MATERIALS AND METHODS}

Study population: This cross sectional study was conducted on students, staff and antenatal patients of a hospital in Benin. A total of 400 apparently healthy subjects aged between 23-27years and parity between $0-4$ volunteered for the study. 100 subjects were in the non-pregnant control group while each of the three trimesters of pregnancy had 100 subjects each. Ethical clearance for the study was obtained from the Ethics and Collaboration Committee of the hospital. Informed consent was also obtained from each subject who volunteered for the study. Volunteers with history of cardiovascular disease in pregnancy, bleeding disorders, diabetes and drugs capable of affecting platelet count were excluded from the study.

Measurement of Blood Pressure: Blood pressure was measured and recorded in $\mathrm{mmHg}$ as follows: after a rest period of about 30 minutes, the systolic and diastolic pressures were measured in each subject in 
the sitting position on the brachial artery using auscultatory method. Diastolic pressure was determined as the disappearance of the Korotkoff's sound.

Blood Sample collection: $5 \mathrm{ml}$ of blood was drawn with minimum stasis from ante-cubital vein of subjects between 9am and 11 am each day in comfortable position and stored in an EDTA anticoagulated tube for platelet analysis. The blood samples were properly labeled and stored at room temperature until ready for analysis. All blood samples were collected between 9am and 11 am each day and analyzed within thirty minutes of collection.

Sample analysis: Analysis of blood was done within thirty minutes of collection and the sample was thoroughly and gently mixed before analysis. Platelet count (PLT), Platelet Width Density (PDW), Plateletcrit (PCT), Mean Platelet Volume (MPV) were determined by flow cytometry using the Swelab Alfa Basic model hematological autoanalyzer (Boule Medical AB, Stockholm, Sweden) at room temperature $\left(27.5 \pm 0.5^{\circ} \mathrm{C}\right)$.
Statistical Analysis: Data were presented as mean value \pm standard error of mean. The means were tested for homogeneity using one way analysis of variance of Micro soft excel 2010 and the significance between means was tested using the Duncan post hoc test of SPSS version 20. A difference between two means was considered to be statistically significant with a $\mathrm{p}$ value $<0.05$.

\section{RESULTS AND DISCUSSION}

Of the four hundred subjects that volunteered for the study, twenty six were disqualified because of the exclusion criteria enumerated in the methodology. Eleven of the disqualified subjects were from the first trimester of pregnancy, while fifteen were from the third trimester of pregnancy. No subject was disqualified from the second trimester of pregnancy and the non-pregnant control. Thus a total of 374 subjects i.e. $93.50 \%$ of the volunteers were involved in the study. Table 1 shows the subjects demographics.

Table 1: Subjects

\begin{tabular}{lllll}
\hline Parameters & $\begin{array}{l}\text { CONTROL } \\
(\mathbf{n = 1 0 0 )}\end{array}$ & $\begin{array}{l}\mathbf{1}^{\text {st }} \text { Trimester } \\
(\mathbf{n = 8 9})\end{array}$ & $\begin{array}{l}\mathbf{2}^{\text {nd }} \mathbf{T r i m e s t e r} \\
(\mathbf{n = 1 0 0})\end{array}$ & $\begin{array}{l}\mathbf{3}^{\text {rd }} \text { Trimester } \\
(\mathbf{n = 8 5})\end{array}$ \\
\hline $\begin{array}{l}\text { Age(yrs) } \\
\text { Parity (range) }\end{array}$ & $24.11 \pm 0.11$ & $23.30 \pm 0.33$ & $25.00 \pm 2.50$ & $25.59 \pm 1.50$ \\
$\begin{array}{l}\text { Blood pressure(mmHg) } \\
\begin{array}{l}\text { Systolic: } \\
\text { Diastolic: }\end{array}\end{array}$ & $1-3$ & $0-1$ & $1-3$ & $1-3$ \\
\hline & $114.17 \pm 2.00$ & $115.44 \pm 2.12$ & $112.23 \pm 2.01$ & $114.05 \pm 2.89$ \\
& $72.64 \pm 1.81$ & $73.11 \pm 1.34$ & $70.23 \pm 1.09$ & $71.45 \pm 0.78$ \\
\hline
\end{tabular}

Table 2: Platelet indices in the non-pregnant control and in three trimesters of pregnancy

\begin{tabular}{|c|c|c|c|c|}
\hline Parameters & Control $(n=100)$ & $\begin{array}{l}\mathbf{1}^{\text {st }} \text { Trimester } \\
(\mathrm{n}=\mathbf{8 9})\end{array}$ & $\begin{array}{l}2^{\text {nd }} \text { Trimester } \\
(\mathrm{n}=100)\end{array}$ & $\begin{array}{l}3^{\text {rd }} \text { Trimester } \\
(n=85)\end{array}$ \\
\hline$\overline{\text { PLT }}$ & 4.32 & $277.83 \pm 36.33^{\#}$ & $193.60 \pm 13.15^{*}$ & $185.50 \pm 11.58^{*}$ \\
\hline MPV & 9.1 & $8.22 \pm$ & 8.40 & 8.0 \\
\hline PDW (\%) & $10.21 \pm 0.18$ & $10.52 \pm 0.22^{\#}$ & $13.44 \pm 0.30 *$ & $13.65 \pm 0.41^{*}$ \\
\hline PCT $(\%)$ & $0.20 \pm 0.02$ & $0.22 \pm 0.03$ & $0.17 \pm 0.01 *$ & $0.16 \pm 0.01 *$ \\
\hline
\end{tabular}

${ }^{*} \mathrm{P}<0.05$ indicates a significant difference when compared to control while ${ }^{\#} \mathrm{P}>0.05$ indicates no significant difference when compared to control.

This study revealed a fall in platelet count in the second and third trimesters of pregnancy (Table 2). This pattern of platelet count fall in the three trimesters of pregnancy was also observed in other studies (Sejeny et al., 1975; Karim et al., 1992). The progressive fall in platelet count from mid-term to labor indicates a direct relationship between the plasma volume changes and the corresponding platelets counts (Shaper et al., 1968). Nevertheless, the progressive fall in platelet count as pregnancy advanced did not cause thrombocytopenia in these trimesters of pregnancy as the values were still within normal range of 150,000 and 450,000 per microliter of blood $\left(150-450 \times 10^{9} / \mathrm{L}\right)$. The decrease in the number of circulating platelets as pregnancy advances are due to normal physiologic changes characterized by increased blood volume, increase in platelet activation, increase platelet aggregation and increased platelet clearance (Matthews, 1990; Fay et al., 1983).Furthermore, placenta size enlarges with progression of gestation and consequently more capturing and destruction of platelet ensue (Shehata et al., 1999). Thrombocytopenia is fairly common in pregnancy and it is caused by accelerated platelet consumption and decreased production (Shamoon et al., 2009). The etiology is unknown but is considered 
to be due to the relative hemodilution in pregnancy (Copplestone, 1992; Dutta, 1998), amplified by the capture and destruction of platelets in the placenta (Shehata et al., 1999). A decreased platelet count as a function of placenta size is emphasized by a study which reported that $70 \%$ of the thrombocytopenic pregnant women were in the third trimester of pregnancy and none in the first trimester (Shamoon et al., 2009; Boehlen et al., 2000). Multiparty with larger placenta size (Monga, 2006) have been shown to have a reducing effect on platelet count possibly due to increased coagulation system in the placenta. Although, Mean platelet volume (MPV) and platelet distribution width (PDW) are known to increase during platelet activation (Vagdatli et al., 2010)' only the latter increased in this study (Table 2). The observed increase in PDW is probably a physiologic compensation for the decreasing platelet count and volume as pregnancy advanced. Platelets having denser granules are bigger in size and metabolically more active (Dogan et al., 2012; Valkila et al., 1994). PDW is more specific than MPV for identification of platelet activity and it is a simple, practical and specific marker for enhanced coagulation (Vagdatli et al., 2010). The plateletcrit in this study also decreased as pregnancy advanced possibly because of the hemodilution (Copplestone, 1992) of mid pregnancy till labour.

The findings from this indicates that platelet count, Mean Platelet Volume (MPV) and plateletcrit reduced as pregnancy traverses its trimesters and this reduction is compensated for, by a physiologic increase in Platelet Width Density (PWD). However, pregnant women who have a setting for thrombocytopenia may be at a higher risk of the effect of this disorder in the third trimester of pregnancy. Thus, PDW should be part of the routine investigations for ante natal women especially in the third trimester as a defect in this compensatory increase may be the reason for the observed effects of thrombocytopenia.

\section{REFERENCES}

Amah-Tariah, F S; Okeja, S O; Dapper, D V (2011). Hematological values in pregnant women in Port Harcourt, Nigeria: serum iron and transferrin, total and unsaturated iron binding capacity and some red cell and platelet indices. Niger.J. physiol. Sci. 26:173-178

Boehlen, F; Hohfeld, P; Extermann, P (2000). Platelet count at term pregnancy: a reappraisal of threshold. Obstet Gynecol.95:29-33
Bonar, J; McNicol, G P; Douglas, AS (1969). Fibrinolytic enzyme system and pregnancy. Brit Med. J. 3: 387-389

Copplestone, J A (1992). Asymptomatic Thrombocytopenia Developing During Pregnancy (Gestational Thrombocytopenia) Clinical Study. Q. J. Med. 8:593.

Dogan, A; Aksoy, F; Icli, A; Arslan, A; Varol, E; Uysal, B A.,et al (2012). Mean platelet volume is associated with culprit lesion severity and cardiac events in acute coronary syndromes without ST elevation. Blood Coagul Fibrinolysis. 23:324-30

Dutta, D C (1998). Physiological Changes during pregnancy, Obstetrics and Gynecology; $4^{\text {th }}$ edition. Calcutta: New central Book Agency.

Fay, R A; Hughes, A O; Farron, N T (1983). Platelets in pregnancy: hypertension in pregnancy. Obstet Gynecol.61:238-240

Kakali, D; Suranjana, S M; Salil, K M (2013). Comparative Study of Platelet Count in Different Trimesters of Pregnancy and in Non-Pregnant Women of Same Age Group. Indian Medical Gazette. 69-73.

Karim, S A; Khurshid, M; Rizvi, J H; Jafarey, S N; Rizwana, I (1992). Platelets and leucocyte counts in pregnancy. J Pak Med Assoc. 42(4):86-87

Liu, X H; Jiang, Y M; Shi, H; Yue, X A; Wang, Y F; Yang, H (2009). Prospective, sequential, longitudinal study of coagulation changes during pregnancy in Chinese women. Int J Gynaecol Obstet. 105(3):240-243

Matthews, J H; Benjamin, S; Gill, D S; Smith, N A (1990). Pregnancy associated thrombocytopenia definition, incidence and naturalhistory. Acta Haematol. 84:24.

Mohapatra, S; Pradhan, B B; Satpathy, U K; Mohanty, A; Patnaik, J R (2007). Platelet Estimation: Its Prognostic Value in Pregnancy Induced Hypertension. Ind. J. Physiol.Pharmacol. 51(2):160-164.

Monga, A, Baker P (2006). Obstetrics by Ten Teachers. $18^{\text {th }}$ ed. London: Hodder Arnold

Ratnoff, O D; Colopy, J E; Prirchard, J A (1954). The blood clotting mechanism during normal parturition. J. Lab. Clin.Med. 44:408-415 
Rodríguez-Dennen, F; Martínez-Ocaña, J; KawaKarasik, S et al (2011). Comparison of Hemodynamic, Biochemical and Hematological Parameters of Healthy Pregnant Women in the Third Trimester of Pregnancy and the Active Labor Phase. Preg.and Child birth. 11:33.

Sejeny, S A; Eastham, R D; Baker, S R (1975); Platelet counts during normal pregnancy. J. Clin Path. 28:812-813

Shamoon, R P; Muhammed, N S; Jaff, M S (2009). Prevalence and etiological classification of thrombocytopenia among a group of pregnant women in Erbil City, Iraq. Turk J Hematol. 26:123-8

Shaper, A G;, Kear, J; Macintosh, D M; Kyober, J; Njama, D (1968). The platelet count, platelet adhesiveness and aggregation and the mechanism of fibrinolytic inhibition in pregnancy and the puerperium. J. Obstet. Gynaec. Brit C Wlth.75(4), 433-441
Shehata, N; Burrows, R; Kelton, J G (1999). Gestational thrombocytopenia. Clin Obstet Gynecol. 42:327-34.

Todd, M E; Thompson, J H; Bowie, E J W; Owen, C A. (1965). Changes in blood coagulation during pregnancy. Mayo clinic. Proc. 40:370-383

Tygart, S G; McRoyan, D K; Spinnato, J A; McRoyan, C J; Kitay, D Z (1986). Longitudinal study of platelet indices during normal pregnancy. Am J Obstet Gynecol. 154(4):883887

Vagdatli, E; Gounari, E; Lazaridou, E; Katsibourlia, E; Tsikopoulou, F; Labrianou, I (2010). Platelet Distribution Width: a simple, practical and specific marker of activation of coagulation. Hippokratia 14(1):28-32.

Valkila, E H; Saenius, J P; Koivula, T A (1994). Platelet indicea in patients with occlusive carotid artery disease. Angiology. 45:361-5 